\title{
HEAD AND NECK CANCER STEM CELL PROTEOMICS
}

\section{Saira Saleem, Sahrish Tariq}

Basic Science Research Laboratory, Shaukat Khanum Memorial Cancer Hospital and Research Centre, Lahore, Pakistan

Received: 20 June 2018 / Accepted 12 March 2019

\begin{abstract}
It is critical to identify the cell of origin of cancer and the genes/proteins/transcriptional/epigenetic factors of that cell. Here, we review studies on head and neck cancer stem cells (CSC) in the hope of developing better understanding of their role highlighting their importance as novel drug targets. CSC model has introduced a hierarchical conceptual framework for the interpretation of intratumour heterogeneity within tumour. This, in turn, has culminated in a major paradigm shift in terms of how different types of cancers can be targeted for treatment. Several malignancies conform to the CSC model of tumour growth yet identification of CSC markers remains a profound challenge.
\end{abstract}

Key words: Chemo- and radio-resistance, head and neck cancer stem cells, proteomics, treatment modalities

\section{Introduction}

There are several prepositions that cancers arise from founder cells that are differentiated or an early progenitor cell or possibly the primary stem cell which undergoes aberrant reprogramming and result in cancer. Stem cells live the longest in the body and exhibit heterogeneity, self-renewal and slow cycling. Since these persist for the lifetime of an individual, these are more likely to accumulate mutations. Cancer cells with properties of stem cells are called cancer stem cells (CSCs) which have tumourigenic and metastatic capacity. Since CSCs are thought to give rise to tumours, understanding their properties, components and physiological roles are crucial. ${ }^{[1]}$ The new hierarchical model of CSC has been introduced [Figure 1] as opposed to clonal evolution of cancer. ${ }^{[2]}$ The ability to isolate these stem/progenitor cells by flow cytometry or magnetic beads and expanding them in culture flask gives us a powerful resource for highthroughput screens that could yield potentially novel therapies for cancer treatment.

There is a mechanistic link between cancer and reprogramming of cell and involves a gain or loss of only a certain number of genes/proteins/transcriptional/

Correspondence: Saira Saleem, Basic Science Research Laboratory, Shaukat Khanum Memorial Cancer Hospital and Research Centre, Johar Town, Lahore 54000, Pakistan. Email: sairas@skm.org.pk epigenetic factors that are dominant enough to induce reprogramming. This is supported by studies that suggested a single transcription factor could be all that is required to induce the reprogramming as long as it is the right factor for the right cell type. ${ }^{[3,4]}$ The four transcription factors, OCT3/4 (octamer-binding transcription factor 3 and 4), SOX-2 (sex-determining region Y), c-MYC and KLF4 oncogene (a gene which in certain circumstances can transform a cell into a tumour cell) shown by Takahashi ${ }^{[5]}$ in their breakthrough work has also been reported to play oncogenic roles.

\section{CSC Evidence in Head and Neck Cancer}

Cancers of the head and neck squamous cell carcinomas (HNSCC) (six major sites: The oral cavity, pharynx [nasopharynx, oropharynx and hypopharynx], larynx, paranasal sinuses, salivary glands and thyroid gland) may arise from any of the lining membranes of the upper aerodigestive tract.

Existence of CSCs has been reported both in human $\mathrm{HN}$ tumours from patients and cell lines derived from primary tumours. After the first report on breast CSCs $\left(\mathrm{CD} 44^{+} \mathrm{CD} 24^{-}\right)$in 2003 , growing evidence supported the concept that a subset of undifferentiated cells, with the ability to self-renewal, in several solid tumours such as brain $\left(\mathrm{CD} 133^{+}\right)$, colon $\left(\mathrm{CD} 133^{+}\right)$, prostate $\left(\mathrm{CD} 44^{+}\right)$, skin $\left(\mathrm{CD} 20^{+}\right)$and pancreas $\left(\mathrm{CD} 44^{+} \mathrm{CD} 24^{+}\right)$is 


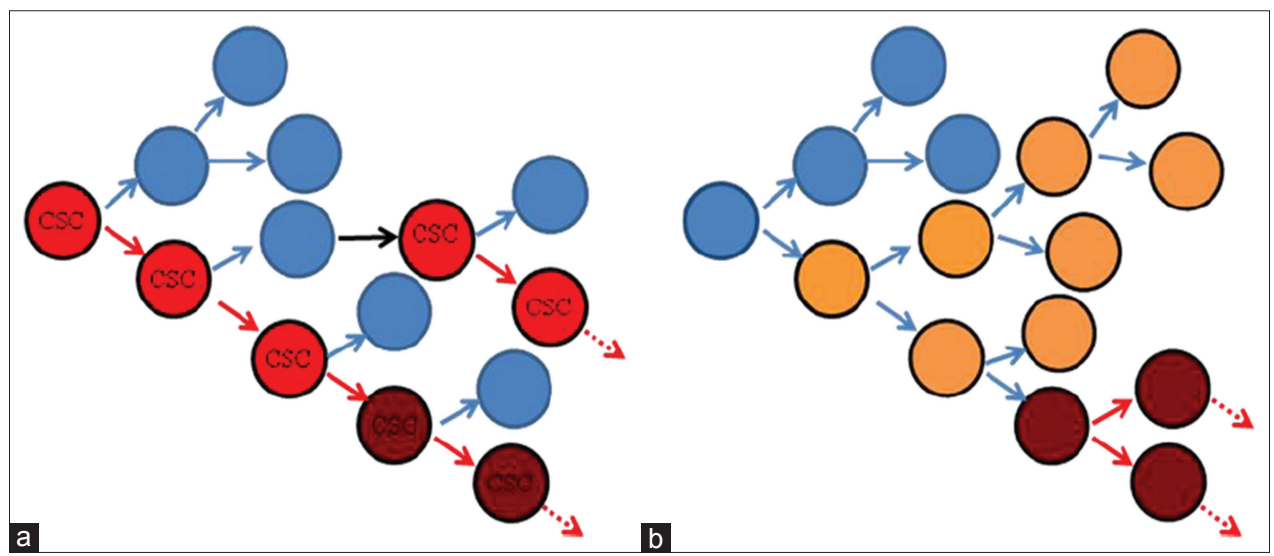

Figure 1: Cancer heterogeneity models. (a) Hierarchical model of cancer stem cells (CSC). The CSC (in red) undergoes a division to give rise to a differentiated daughter cell (blue) and another CSC (red, self-renewal depicted by red arrow). The CSC by virtue of its infinite proliferative potential will continue to divide as above (dotted arrow). The differentiated cell may undergo a few divisions before terminal differentiation or senescence or cell death as the case may be. The CSC may undergo clonal evolution and acquire even greater tumourigenicity and/or chemoresistance and/or radioresistance (brown). Alternatively, a differentiated cell may dedifferentiate and acquire tumourigenicity (black arrow) and be converted to a CSC. (b) Clonal evolution model. Normal cells (blue) acquire mutations stochastically (yellow) and over successive divisions, and due to accrual of several mutations, these cells become transformed (red) and/or acquire chemo- and/or radio-resistance and can divide indefinitely (dotted arrow). Figure from Mitra et al., 2011[2]

generated, maintained and regrow into the bulk tumour population. ${ }^{[6-13]}$ The cluster of differentiation (CD) is a protocol used for the identification and investigation of cell surface molecules present on cells. Prince et al. contributed the first report for the existence of CSCs in $\mathrm{HN}$ cancer with the use of CD44 as a marker for CSCs from primary tumours. ${ }^{[14]}$ This study also performed the gold standard CSC test, the limiting dilution transplantation assay (LDA), in immune-compromised mice that determine the minimum number (5000) of CD $44^{+}$cells for tumour formation while CD44- cells failed to form tumours in the mice. Another study in the same year demonstrated that clonogenicity is restricted to a subpopulation of total cells within HNSCC each of which can generate populations with full range of heterogeneity present in parent cell line reflecting a stem cell pattern. ${ }^{[15]}$ They found three different colonies, namely holoclones (compact, round and least differentiated), meroclones (scattered cells) and paraclones (more scattered cells having the highest degree of differentiation) from parent cell lines. Only holoclones resembling tumour contained CSCs while other two with more scattered cells were less likely to contain CSC [Figure 2]. Several observations made in these studies on HNSCC cell lines indicated that criteria sufficient to indicate persistence of stem cell pattern i.e., self-renewal, amplifying hierarchy and ability of differentiation are met.

Head and neck CSCs (HNCSCs) live in nearby vicinity of accompanying blood vessels known as the perivascular niche which provides a conducive environment for them to flourish and multiply. ${ }^{[17,18]}$ Mutations attained overtime, in normal stem cells, empowers these cells for self-renewing property within an alternative niche which, in turn, becomes a proliferative hub for other mutant stem cells, hence, converting them to CSC. Alison et al. reported that self-renewal pathways (WNT, Hedgehog and Notch) impart vastly differentiating property to CSCs and make them unique for tumour progression. ${ }^{[19]}$ A study reported that enriched $\mathrm{CD} 133^{+} \mathrm{CSC}$ from four OSCC cell lines, PCI-4A, PCI-8, PCI-9A and PCI-13, showed reduced sensitivity to paclitaxel through ATP-binding cassette (ABC) drug transporters. ${ }^{[20]}$

\section{Proteomics of Head and Neck Cancer}

From a highly invasive oral cancer cell line UM1, non-adherent CSC-like cells $\left(\mathrm{SOX} 2^{\text {high }} \mathrm{OCT} 4^{\text {high }}\right.$ SOX $9^{\text {high }}$ CD $44^{\text {high }}$ HIF- $1 \alpha^{\text {low } P G K-1 ~}{ }^{\text {low }}$ ) and adherent non-CSC UM1 cells were isolated. A lowly invasive UM2 oral cancer cell line was used as a control. Using 


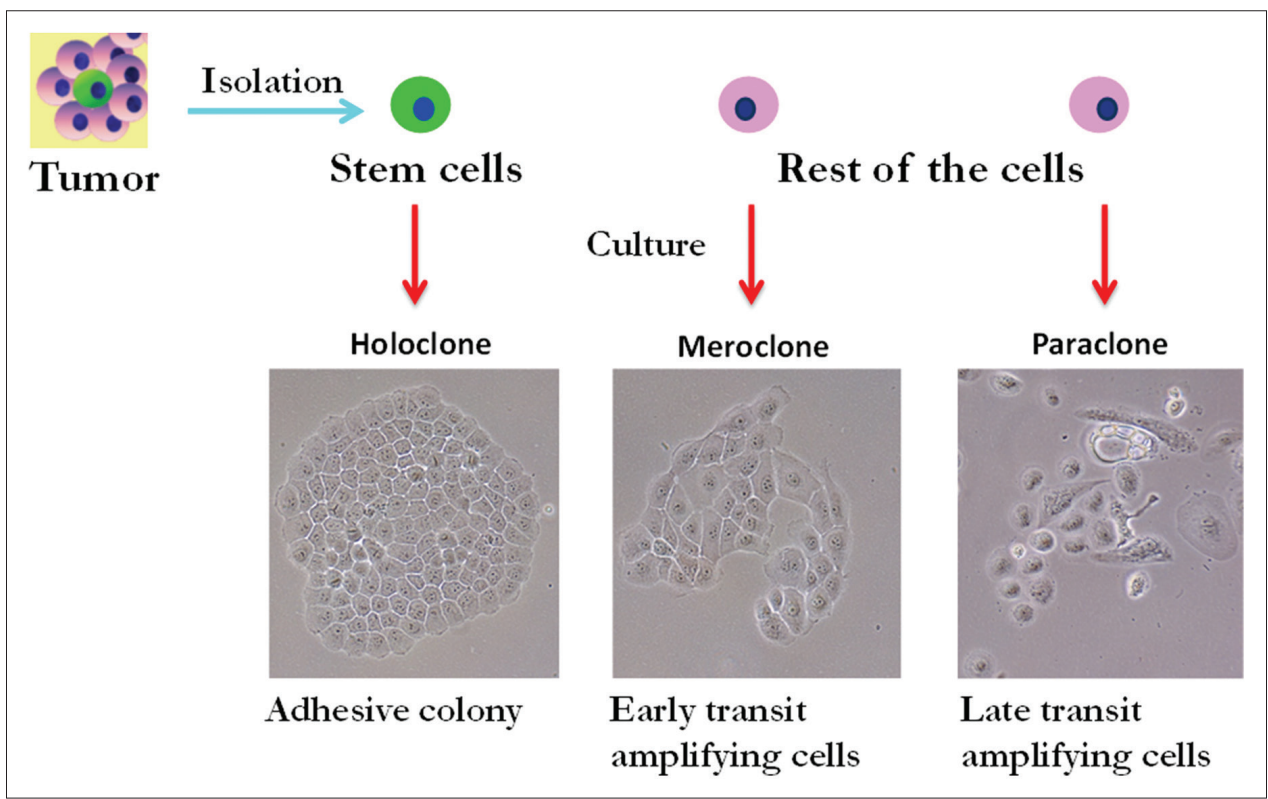

Figure 2: Clonal morphology of human oral squamous cell carcinoma (OSCC)-derived cell line. An OSCC-derived cell line grown under serum-free conditions. Holoclones are characterised by round colony outlines and small, closely packed cells. Meroclones have larger and somewhat more flattened cells that remain in contact with each other in the central region but at the periphery of the colony have separated and acquired an ovoid outline. Paraclones consist largely of flattened scattered ovoid cells, few of which remain in contact. Figure modified from Costea et al., 2006 ${ }^{[16]}$. Image courtesy Professor Dr. Daniela Costea (University of Bergen, Norway)

quantitative tandem mass tagging, a significant proteomic alteration between CSC-like and non-CSC UM1 cells was observed. In particular, transcriptional coactivator CBP (CREB-binding protein) and phosphorylated CREB-1 (cyclic AMP response element-binding protein 1) were significantly upregulated in CSC-like UM1 cells versus non-CSC UM1 cells, suggesting that the CREB pathway is activated in the CSC-like cells. ${ }^{[2]}$ Although there is ample evidence for the existence of CSCs, yet their isolation faces challenges because a definite marker has not been identified. Several cell surface receptors and intracellular proteins have been reported to be differently expressed between stem cells and differentiated mature cells. In HN cancer tissues, little progress has been made to mark CSCs. The widely accepted markers [Table 1] are also expressed by other basal layer cells which only allow for enrichment of CSCs instead of the isolation of pure cell population. The ambiguity of CSC markers is persisting despite large body of literature and information. ${ }^{[22]}$ The suggested cell surface marker of CSCs in OSCC is hyaluronan receptor $\mathrm{CD} 44 ;^{[14]}$ however, there are contradictory reports on utility of CD44 with various isoforms as a marker for $\mathrm{HNCSCs}^{[23]}$ and its role was questioned by a study in
Table 1: Markers of HNCSCs

\begin{tabular}{l|c}
\hline Marker & References \\
\hline $\mathrm{CD} 44^{+}(\mathrm{CK} 5, \mathrm{CK} 14, \mathrm{BMI} 1)$ & {$[14]$} \\
\hline $\mathrm{ALDH}^{\text {high }}$ (also+ve for CD44) & {$[27]$} \\
\hline $\mathrm{OCT}_{4}$, Nanog, CD117, Nestin, CD133, ABCG2 & {$[28]$} \\
\hline $\mathrm{CD}^{+} 33^{+}$ & {$[29]$} \\
\hline $\mathrm{CD}_{4}$, OCT4, SOX2, SOX9 & {$[21]$} \\
\hline
\end{tabular}

HNCSCs: Head and neck cancer stem cells

which both $\mathrm{CD} 44^{+}$and $\mathrm{CD} 44^{-}$cells from squamospheres regenerated spheres from single cell suspension. ${ }^{[24]}$ The expression of CD44 variants was associated with regional metastasis $(\mathrm{CD} 44 \mathrm{v} 3)$, perineural invasion $(\mathrm{CD} 44 \mathrm{v} 6)$ and radiation failure $(\mathrm{CD} 44 \mathrm{v} 10){ }^{[25]}$ Cells expressing high CD29 and CD44 which can be used as markers to enrich CSCs in human SCC exhibiting molecular characteristics of EMT (a mechanism imparting stem-like properties to differentiated cells) suggest that CSC-associated pathways were involved in EMT. The first report of lung metastasis of $\mathrm{HN}$ cancer stem-like cells describing transcription factor SNAIL1 (zinc finger protein), oncogene BMI-1 (polycomb complex protein) and oxidation enzyme ALDH 
(aldehyde dehydrogenase) as worst prognostic factors, strengthened the link between EMT and stemness in HN cancer. ${ }^{[26]}$

Oral cancer cell line proteome was studied by MALDI-TOF MS/MS and IPA analysis predicted that at least 18 proteins including cell cycle regulator CLIC1 (chloride intracellular channel protein 1) and antigen processor proteasome activator complex subunit. ${ }^{[30]}$ Two-dimensional electrophoresis and peptide mass fingerprinting detection of enolase-1 in the whole saliva were shown to be significantly higher for OSCC patients than for healthy individuals. ${ }^{[31]} \mathrm{A}$ low-molecular-weight candidate thioredoxin was detected by LC-MALDI-MSMS in oral fluids from OSCC patients and matched control patients, and the average level of thioredoxin in cancer samples was found to be about
3 times higher than that in normal samples $(P<0.01) .{ }^{[32]}$ In recent study, a statistically significant higher abundance demonstrated that complement factor b, C3 (complement component 3), glycoprotein C4B (C4-binding protein), serine protease inhibitor SERPINA1 (alpha-1-antitrypsin) and signal transduction glycoprotein leucine-rich-alpha-2 glycoprotein are associated with the risk of developing OSCC. ${ }^{[33]}$ A total of 26 proteins representing 12 unique gene products were identified hypopharyngeal squamous cell carcinoma by 2D-DIGE and MALDI-TOF/TOF MS. The upregulated proteins were AHSG (alpha-2-HSglycoprotein), complement C4-B, haemoglobin-binding liver protein $\mathrm{Hp}$ (haptoglobin), marker of inflammation C-reactive protein and copper-binding enzyme CP (ceruloplasmin), whereas the downregulated proteins were plasma protein ALB (serum albumin), component

Table 2: Drugs which kill cancer stem cells

\begin{tabular}{|c|c|c|c|c|c|}
\hline Drug & Compound & Structure & Target & Mode of action & References \\
\hline Cisplatin & Cis-diamminedichloroplatinum & & $\begin{array}{l}\text { NFkB - an } \\
\text { inducible } \\
\text { transcription } \\
\text { factor present in } \\
\text { an inactive form } \\
\text { in the cytoplasm. } \\
\text { In response to } \\
\text { appropriate } \\
\text { signals, for } \\
\text { example, TNF- } \alpha \text {, } \\
\text { it is activated } \\
\text { and transported } \\
\text { to the nucleus } \\
\text { where it binds to } \\
\text { DNA and activates } \\
\text { transcription. }\end{array}$ & $\begin{array}{l}\text { Nuclear transport } \\
\text { of p16, recruitment } \\
\text { of gigaxonin for the } \\
\text { ubiquitination of } \\
\text { NFKB, inhibition of } \\
\text { NFKB, decreased } \\
\text { expression of } \\
\text { NFKB transcribed } \\
\text { proteins and } \\
\text { triggering of } \\
\text { apoptosis. }\end{array}$ & [34] \\
\hline $\begin{array}{l}\text { Bortezomib } \\
\text { (Valcade) + } \\
\text { TRAIL }\end{array}$ & $\begin{array}{l}(1 R)-3-\text { methyl } \\
-1-(\{(2 S)-3-\text { phenyl-2-[(pyrazin } \\
-2 \text {-ylcarbonyl) amino] } \\
\text { propanoyl\} amino) butyl] } \\
\text { boronic acid }\end{array}$ & & TRAIL receptor 2 & $\begin{array}{l}\text { Sensitisation } \\
\text { of TRAIL-R2 to } \\
\text { TRAIL, Increased } \\
\text { activation of } \\
\text { caspase } 8,9 \text { and } \\
3 \text {, apoptosis } \\
\text { through type I } \\
\text { pathway, Increased } \\
\text { expression of } \\
\text { TRAIL-R2, cyto- } \\
\text { chrome-c release, } \\
\text { activation of } \\
\text { caspase } 9 \text { and } 3 \text {, } \\
\text { apoptosis through } \\
\text { type II pathway. }\end{array}$ & [36] \\
\hline
\end{tabular}


of the renin-angiotensin system angiotensinogen, SERPINA3 (alpha-1-antichymotrypsin), immunoglobulin component IGHG3 (Ig gamma-3 chain $\mathrm{C}$ region), blood clot component fibrinogen gamma chain, cholesterol transporter apolipoprotein A-I and immunoglobulin component and $\mathrm{Ig}$ kappa chain $\mathrm{C}$ region.

\section{Current Treatment Modalities in Head and Neck Cancer and Protein-specific Drugs in Trial}

This is imperative to switch from current non-specific treatments to personalised medicine. Chemoresistance due to the heterogeneous group of tumour cells is wellreported impediment for failure of different therapeutic strategies. The challenges become multifold when disease spreads from its primary site. Even after the recent advancements in therapies for HN cancers, longterm survival rate is still poor. Since decades platinumbased agents (cisplatin) are being used as the first-line chemotherapeutic drugs for HN cancers, but their exact mechanism of action is not known. A p16-mediated cell cycle arrest with the use of cisplatin [Table 2] was found to cause downregulation of tumour suppressor genes and suppression of $\mathrm{p} 16$ has been linked to cisplatin resistance in HN cancer. ${ }^{[34]}$ An iTRAQ-based MALDIMS proteomics study on four human HNSCC cell lines: Cisplatin-sensitive UM-SCC-23, UM-SCC-23-CDDPR with acquired cisplatin resistance, naturally cisplatinresistant UM-SCC-81B and UM-SCC-23/WR with acquired 5-fluorouracil resistance proposed $\alpha$-Enolase as a true cisplatin chemoresistance factor of 13 proteins which were found to be associated with multidrug resistance. ${ }^{[35]}$

Bortezomib is the first therapeutic FDA approved proteosome inhibitor treating relapsed multiple myeloma and mantle cell lymphoma. In HN cancers, its solitary role has not been quite promising however, combining bortezomib with TRAIL (tumor necrosis factor related apoptosis inducing ligand) receptor agonists produced a synergistic cytotoxic effect in TRAIL-resistant HPVpositive cells [Table 2]. ${ }^{[36]}$ A relatively new solid tumour treatment modality ALA-PDT (5-aminolevulinic acid-mediated photodynamic therapy) has been reported to reduce ALDH1 activity, CD44 positivity (widely accepted CSC markers), self-renewal and invasion of CSC in $\mathrm{HN}$ cancers resulting in enhanced chemosensitivity and apoptotic ability through NF$\mathrm{kB} / \mathrm{JNK}$ signalling and decrease migration capacity of oral cancer cells by downregulation of FAK (focal adhesion kinase) and ERK (extracellular signal-regulated kinase). ${ }^{[37]}$ One compound, salinomycin, reduces the proportion of CSCs by $>100$-fold relative to paclitaxel, a commonly used cancer chemotherapeutic drug. ${ }^{[38]}$ The combination of cetuximab and the hedgehog inhibitor IPI-926, the proliferation inhibitors, is more active than either single agent in patient-derived xenograft models of HNSCC. ${ }^{[39]}$

\section{Conclusions}

We have presented an update in the area of head and neck cancer research highlighting a CSC model, identification of bona fide CSC marker is paramount. The high-throughput techniques in the field of proteomics can play a powerful role in achieving this goal which might change the course of medicine. A better understanding of cycling dynamics at molecular level within hyper- and hypo-proliferative cell populations after radio- and chemo-therapy is needed to better treat cancer. Thus, regardless of, whether the resistance is primary or acquired, digging into the molecular mechanisms involved and discovering, the definitive therapies targeting CSCs have undoubtedly become a pivotal issue in the treatment of human cancers and so far extraordinary efforts have been put into, to describe some incredible chemotherapeutic agents that selectively target CSCs by aiming the various pathways involved in regulation of these cells. Other salient mechanisms which can invalidate the therapeutic modalities include decreased intracellular drug accumulation, drug inactivation, perturbations in signal transduction pathways and apoptosis-/autophagyrelated chemoresistance.

\section{Acknowledgment}

This study is supported by grants from Shaukat Khanum Memorial Cancer Hospital and Research Centre, Lahore, Pakistan.

\section{Conflict of Interest}

The authors declare that they have no conflict of interest. 


\section{References}

1. Visvader JE, Lindeman GJ. Cancer stem cells in solid tumours: Accumulating evidence and unresolved questions. Nat Rev Cancer 2008;8:755-68.

2. Mitra D, Malkoski SP, Wang XJ. Cancer stem cells in head and neck cancer. Cancers (Basel) 2011;3:415-27.

3. Nutt SL, Heavey B, Rolink AG, et al. Commitment to the B-lymphoid lineage depends on the transcription factor pax5. Nature 1999;401:556-62.

4. Cobaleda C, Jochum W, Busslinger M. Conversion of mature $\mathrm{B}$ cells into $\mathrm{T}$ cells by dedifferentiation to uncommitted progenitors. Nature 2007;449:473-7.

5. Takahashi K, Yamanaka S. Induction of pluripotent stem cells from mouse embryonic and adult fibroblast cultures by defined factors. Cell 2006;126:663-76.

6. Al-Hajj M, Wicha MS, Benito-Hernandez A, et al. Prospective identification of tumorigenic breast cancer cells. Proc Natl Acad Sci U S A 2003;100:3983-8.

7. Fang D, Nguyen TK, Leishear K, et al. A tumorigenic subpopulation with stem cell properties in melanomas. Cancer Res 2005;65:9328-37.

8. Galli R, Binda E, Orfanelli U, et al. Isolation and characterization of tumorigenic, stem-like neural precursors from human glioblastoma. Cancer Res 2004;64:7011-21.

9. Li C, Heidt DG, Dalerba $\mathrm{P}$, et al. Identification of pancreatic cancer stem cells. Cancer Res 2007;67:1030-7.

10. Patrawala L, Calhoun T, Schneider-Broussard R, et al. Highly purified CD44+ prostate cancer cells from xenograft human tumors are enriched in tumorigenic and metastatic progenitor cells. Oncogene 2006;25:1696-708.

11. Ricci-Vitiani L, Lombardi DG, Pilozzi E, et al. Identification and expansion of human colon-cancer-initiating cells. Nature 2007;445:111-5.

12. Singh SK, Clarke ID, Terasaki M, et al. Identification of a cancer stem cell in human brain tumors. Cancer Res 2003;63:5821-8.

13. Singh SK, Hawkins C, Clarke ID, et al. Identification of human brain tumour initiating cells. Nature 2004;432:396-401.

14. Prince ME, Sivanandan R, Kaczorowski A, et al. Identification of a subpopulation of cells with cancer stem cell properties in head and neck squamous cell carcinoma. Proc Natl Acad Sci U S A 2007;104:973-8.

15. Harper LJ, Piper K, Common J, et al. Stem cell patterns in cell lines derived from head and neck squamous cell carcinoma. J Oral Pathol Med 2007;36:594-603.

16. Costea DE, Tsinkalovsky O, Vintermyr OK, et al. Cancer stem cells new and potentially important targets for the therapy of oral squamous cell carcinoma. Oral Dis 2006;12:443-54.

17. Gómez-Gaviro MV, Lovell-Badge R, Fernández-Avilés F, et al. The vascular stem cell niche. J Cardiovasc Transl Res 2012;5:618-30.

18. Ritchie KE, Nör JE. Perivascular stem cell niche in head and neck cancer. Cancer Lett 2013;338:41-6.

19. Alison MR, Lim SM, Nicholson LJ. Cancer stem cells:
Problems for therapy? J Pathol 2011;223:147-61.

20. Dean M, Fojo T, Bates S. Tumour stem cells and drug resistance. Nat Rev Cancer 2005;5:275-84.

21. Misuno K, Liu X, Feng S, et al. Quantitative proteomic analysis of sphere-forming stem-like oral cancer cells. Stem Cell Res Ther 2013;4:156.

22. Jaggupilli A, Elkord E. Significance of CD44 and CD24 as cancer stem cell markers: An enduring ambiguity. Clin Dev Immunol 2012;2012:708036.

23. Ponta H, Sherman L, Herrlich PA. CD44: From adhesion molecules to signalling regulators. Nat Rev Mol Cell Biol 2003;4:33-45.

24. Lim YC, Oh SY, Cha YY, et al. Cancer stem cell traits in squamospheres derived from primary head and neck squamous cell carcinomas. Oral Oncol 2011;47:83-91.

25. Wang SJ, Wong G, de Heer AM, et al. CD44 variant isoforms in head and neck squamous cell carcinoma progression. Laryngoscope 2009;119:1518-30.

26. YuCC,LoWL, Chen YW, etal. Bmi-1 regulates snail expression and promotes metastasis ability in head and neck squamous cancer-derived ALDH1 positive cells. J Oncol 2011;2011: 609259.

27. ClayMR, TaborM, OwenJH, etal. Single-markeridentification of head and neck squamous cell carcinoma cancer stem cells with aldehyde dehydrogenase. Head Neck 2010;32: 1195-201.

28. Chiou SH, Yu CC, Huang CY, et al. Positive correlations of oct-4 and nanog in oral cancer stem-like cells and high-grade oral squamous cell carcinoma. Clin Cancer Res 2008;14: 4085-95.

29. Zhang Q, Shi S, Yen Y, et al. A subpopulation of CD133(+) cancer stem-like cells characterized in human oral squamous cell carcinoma confer resistance to chemotherapy. Cancer Lett 2010;289:151-60.

30. Karsani SA, Saihen NA, Zain RB, et al. Comparative proteomics analysis of oral cancer cell lines: Identification of cancer associated proteins. Proteome Sci 2014;12:3.

31. Katakura A, Yamamoto N, Sakuma T, et al. A screening test for oral cancer using saliva samples: Proteomic analysis of biomarkers in whole saliva. J Oral Maxillofac Surg Med Pathol 2015;27:1-5.

32. Hu S, Yu T, Xie Y, et al. Discovery of oral fluid biomarkers for human oral cancer by mass spectrometry. Cancer Genomics Proteomics 2007;4:55-64.

33. Kawahara R, Bollinger JG, Rivera C, et al. A targeted proteomic strategy for the measurement of oral cancer candidate biomarkers in human saliva. Proteomics 2016;16:159-73.

34. Veena MS, Wilken R, Zheng JY, Gholkar A, Venkatesan N, Vira $\mathrm{D}$, et al. $\mathrm{P} 16$ protein and gigaxonin are associated with the ubiquitination of NFKB in cisplatin-induced senescence of cancer cells. J Biol Chem 2014;289:34921-37.

35. Nishimura K, Tsuchiya Y, Okamoto $\mathrm{H}$, et al. Identification of chemoresistant factors by protein expression analysis with iTRAQ for head and neck carcinoma. Br J Cancer 
2014;111:799-806.

36. Bullenkamp J, Raulf N, Ayaz B, et al. Bortezomib sensitises TRAIL-resistant HPV-positive head and neck cancer cells to TRAIL through a caspase-dependent, E6-independent mechanism. Cell Death Dis 2014;5:e1489.

37. Yu CH, Yu CC. Photodynamic therapy with 5-aminolevulinic acid (ALA) impairs tumor initiating and chemo-resistance property in head and neck cancer-derived cancer stem cells. PLoS One 2014;9:e87129.

38. Gupta PB, Onder TT, Jiang G, et al. Identification of selective inhibitors of cancer stem cells by high-throughput screening. Cell 2009;138:645-59.

39. Bowles DW, Keysar SB, Glogowska MJ, et al. A pilot study of cetuximab and the hedgehog inhibitor IPI-926 in recurrent/metastatic $(\mathrm{R} / \mathrm{M})$ head-and-neck squamous cell carcinoma. Int J Radiat Oncol Biol Phys 2015;88:511.

\section{Authorship Contributions}

Concept and Design: SS, ST; Data Collection and interpretation: SS, ST; Literature review and writing: SS, ST; Manuscript approval: SS, ST 